\title{
Additive Main Effects and Multiplicative Interaction and Genotype Main Effect and Genotype by Environment Interaction Effects-Biplot Analysis of Sorghum Grain Yield in Uganda
}

\author{
Charles Andiku ${ }^{1}$, Geofrey Lubadde ${ }^{2}$, Charles J. Aru ${ }^{1}$, Michael A. Ugen ${ }^{1} \&$ Johnie Ebiyau ${ }^{1}$ \\ ${ }^{1}$ National Semi Arid Resources Research Institute, Soroti, Uganda \\ ${ }^{2}$ Department of Crop Production and Management, Faculty of Agriculture and Animal Sciences, Busitema \\ University, Tororo, Uganda \\ Correspondence: Charles Andiku, National Semi Arid Resources Research Institute, P.O. Box 56, Soroti, Uganda. \\ E-mail: andikuc@gmail.com
}

\author{
Received: March 8, $2020 \quad$ Accepted: April 14, $2020 \quad$ Online Published: May 15, 2020 \\ doi:10.5539/jas.v12n6p98 URL: https://doi.org/10.5539/jas.v12n6p98
}

\begin{abstract}
Genotype-by-environment interaction analysis is vital for cultivar release, and to identify suitable crop production sites. The current study aimed to determine sorghum grain yield stability and adaptability and to identify the most informative and representative environments for sorghum grain yield performance in Uganda. Sorghum grain yield data of eight (08) genotypes; ICSR 160, IS8193, IESV92043DL, IESV92172DL, GE17/1/2013A, GE35/1/2013A, SESO1, and SESO3 tested across eight (08) major sorghum production area in Uganda for two consecutive seasons of 2017 using randomised complete block design with 2 replications were analysed via Additive Main effects and Multiplicative Interaction (AMMI) and Genotype Main Effect and Genotype by Environment interaction effects (GGE) using PB tools. Genotype IESV92043DL was the ideal genotype in the entire test environments with mean grain yield of $2783 \mathrm{~kg} \mathrm{ha}^{-1}$ however genotype ICSR $160 \mathrm{had}$ the highest grain yield of $2823 \mathrm{~kg} \mathrm{ha}^{-1}$ across all the test environment. On the other hand, GE17/1/2013A was the most stable and adapted genotype across all the test environment. Of the eight (08) environments tested, biplot analysis precisely grouped the test environments into two presumed mega-environments with the best genotype being IS8193 and ICSR 160. Out of eight (08) trial sites, two (02) environments; Abi and Mayuge were the most representative and informative environment for sorghum grain yield performance in Uganda.
\end{abstract}

Keywords: sorghum (Sorghum bicolor), multiplicative models, genotype, and yield stability

\section{Introduction}

Environment is important in determining the performance of crop genotypes especially for quantitative variables. Likewise the multiplicative effect of the genotype by environment [genotype by environment interaction (GEI)] further complicates the expressivity of the variables resulting in selection. This directs plant breeders to select genotypes that are suitable for certain environment. It is important to study genotypes response to different environments and henceforth select cultivars suitable for specific or diverse environments. However, cultivars that are adapted to diverse environments are the most desirable in breeding therefore understanding genotype by environment $(\mathrm{GxE})$ interaction is very key in a plant breeding program before the variety is released to the uptake pathway. The yield potential of a variety is controlled by both the genetic and various environmental factors that vary over the years and locations. The study of quantitative traits like grain yield is further convoluted by GxE interaction; especially across many trial locations (Kaya et al., 2002). Therefore, evaluation of newly developed varieties across several environments is fundamental to estimate the magnitude of GEI, and for cultivar recommendation. Several statistical approaches have been used to analyse GE1 for recommending specific or general selection in plant breeding. As noted by Lubadde et al. (2017), more than one method should be used for better comparison. In this study the Additive Main effects and Multiplicative Interaction (AMMI) and the Genotype Main Effect and Genotype by Environment interaction effects (GGE) models was adopted. Nyaligwa et al. (2018) acknowledged that AMMI and GGE models have been used by many breeders to analyse GE1. AMMI employs both analysis of variance (ANOVA) and principle component analysis (PCA) (Zobel et al., 1988) to analyse the main effects (additive effect) and the non-additive residual effect (Akter et al., 2014) 
respectively to ascertain GEI for trait of interest such as sorghum grain yield in this current study. While GGE biplots on the other hand display both genotype and genotype by environment disparity for traits (Crossa et al., 2002). In this current study, both AMMI and GGE biplot was used for estimating yield stability and adaptability of improved sorghum genotype over the major sorghum production areas in Uganda as excellent tools for visual display and interpretation of multi environments data (Rakshit et al., 2017). Therefore, the objectives of this study were to (i) determine sorghum grain yield stability and adaptability, (ii) identify the most discriminating (informative) and representative environments for sorghum grain yield performance in Uganda and (iii) determine the presence of sorghum production mega environments in Uganda.

\section{Materials and Methods}

\subsection{Trial Sites}

The trial was conducted at eight (08) different sites namely Arua, Iganga, Mayuge, Namutumba, Pallisa, Serere, Oyam and Kitgum (Table 1 and Figure 1) that represent the major sorghum production areas in Uganda for two consecutive seasons (first and second seasons) of 2017. Each site and two consecutive seasons formed the eight (08) environment in which sorghum grain yield data were collected for AMMI and GGE biplot analysis.

\subsection{Experimental Materials and Design}

Eight (08) genotypes including two checks (SESO1 and SESO3) (Table 2) were used in this study. The trials were arranged in randomised complete block design with two replications per location. Each genotype was planted in a plot with 4 rows at spacing of $60 \mathrm{~cm}$ apart and $20 \mathrm{~cm}$ between plants within the row and each plot was measuring $4 \mathrm{~m}$ long.

Table 1. Characteristics of the locations used in the study

\begin{tabular}{|c|c|c|c|c|c|c|c|}
\hline \multirow[t]{2}{*}{ Code } & \multirow[t]{2}{*}{ Location } & \multicolumn{2}{|c|}{ Geographical position } & \multirow{2}{*}{$\begin{array}{l}\text { Elevation } \\
\mathrm{m}\end{array}$} & \multirow{2}{*}{$\begin{array}{l}\text { Mean Temp } \\
{ }^{\circ} \mathrm{C}\end{array}$} & \multirow{2}{*}{$\begin{array}{l}\text { Annual } \\
\text { Rainfall } \\
\mathrm{mm}\end{array}$} & \multirow[t]{2}{*}{ Agro-ecologies } \\
\hline & & Latitude & Longitude & & & & \\
\hline E1 & Arua & $3^{\circ} 1^{\prime} 9^{\prime \prime} \mathrm{N}$ & $30^{\circ} 55^{\prime} 51^{\prime \prime} \mathrm{E}$ & 1215 & 23.9 & 1404 & West Nile farmlands \\
\hline E2 & Iganga & $0^{\circ} 36^{\prime} 33^{\prime \prime} \mathrm{N}$ & $33^{\circ} 28^{\prime} 7^{\prime \prime} \mathrm{E}$ & 1120 & 23.3 & 1313 & Lake Victoria Crescent \\
\hline E3 & Kitgum & $3^{\circ} 16^{\prime} 42^{\prime \prime} \mathrm{N}$ & $32^{\circ} 53^{\prime} 12^{\prime \prime} \mathrm{E}$ & 760 & 24.1 & 1125 & North Eastern Central Grass Bush farmlands \\
\hline E4 & Mayuge & $0^{\circ} 27^{\prime} 35^{\prime \prime} \mathrm{N}$ & $33^{\circ} 28^{\prime} 49^{\prime \prime} \mathrm{E}$ & 1,190 & 22.3 & 979 & Lake Victoria Crescent \\
\hline E5 & Namutumba & $0^{\circ} 50^{\prime} 10^{\prime \prime} \mathrm{N}$ & $33^{\circ} 41^{\prime} 10^{\prime \prime} \mathrm{E}$ & 1,080 & 22.0 & 1322 & Lake Kyoga Basin \\
\hline E6 & Oyam & $2^{\circ} 26^{\prime} 24^{\prime \prime} \mathrm{N}$ & $32^{\circ} 23^{\prime} 22^{\prime \prime} \mathrm{E}$ & 900 & 21.6 & 1500 & Northern moist farmlands \\
\hline E7 & Pallisa & $1^{\circ} 8^{\prime} 42^{\prime \prime} \mathrm{N}$ & $33^{\circ} 42^{\prime} 34^{\prime \prime} \mathrm{E}$ & 1,070 & 23.4 & 1353 & Lake Kyoga Basin \\
\hline E8 & Serere & $1^{\circ} 29^{\prime} 39^{\prime \prime} \mathrm{N}$ & $33^{\circ} 27^{\prime} 19^{\prime \prime} \mathrm{E}$ & 1140 & 23.8 & 1362 & Lake Kyoga Basin \\
\hline
\end{tabular}




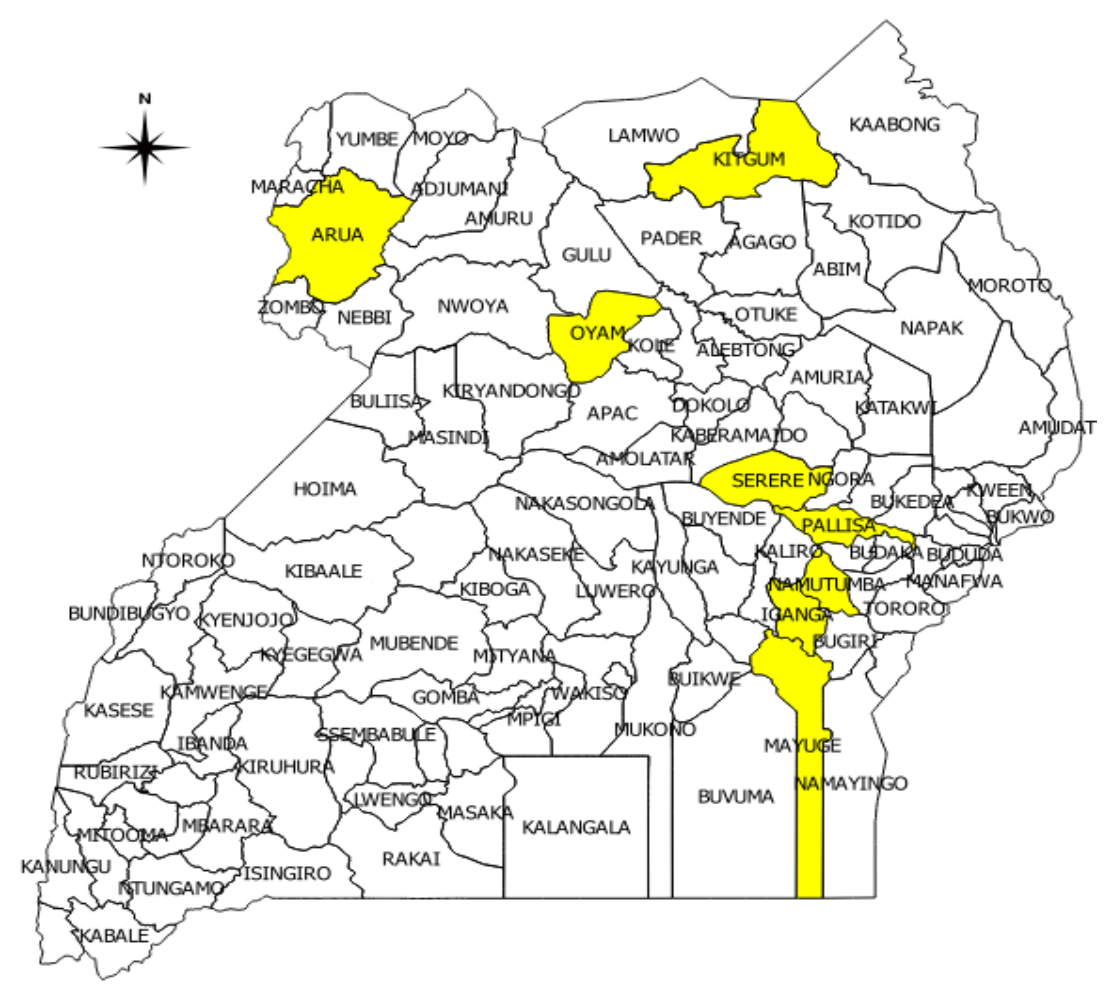

Figure 1. Map of Uganda showing the locations (marked in yellow) used in the study

The trials were weeded manually thrice for good crop establishment and no fertilizer was applied during the crop growing cycle however they were sprayed with cypermethrin to control pests at four weeks after crop emergence, then at intervals of two weeks for 6 weeks.

Table 2. List of sorghum genotype used in this study

\begin{tabular}{|c|c|c|c|c|}
\hline Code & Genotypes Source & Pedigree or Origin & Variety status & Special attributes \\
\hline G1 & GE17/1/2013A (GE17) & USA, Perdue University & Pure line & Resistant to Smut and Striga, and early maturity \\
\hline G2 & GE35/1/2013A (GE35) & Texas & Pure line & Sweet stalk and seed, and resistant to striga \\
\hline G3 & ICSR 160 & $\begin{array}{l}{[(\text { IS } 12622 \mathrm{Cx} 555)} \\
\times(\text { IS } 3612 \mathrm{Cx} 2219 \mathrm{~B})-5-1 \\
\times \text { E 35-1], ICRISAT }\end{array}$ & Pure line & $\begin{array}{l}\text { Suitable for lager beer production and drought } \\
\text { tolerant/stay green trait. }\end{array}$ \\
\hline G4 & IESV 92043DL & KARI Mtama $1 \times$ Seredo, ICRISAT & Pure line & $\begin{array}{l}\text { Resistant to midge, drought tolerant, juicy sweet stalk } \\
\text { suitable for forage. }\end{array}$ \\
\hline G5 & IESV92172DL & ICRISAT & Pure line & $\begin{array}{l}\text { Short height and medium maturity with high } \\
\text { threshability }\end{array}$ \\
\hline G6 & IS8193 & Land Race from East Africa, ICRISAT & Pure line & Resistant to bird damage, drought and Striga tolerant. \\
\hline G7 & SESO1 (M91057)-Check 1 & [GPR $148 \times$ E35-1] $\times$ CS 3541) & $\begin{array}{l}\text { Released variety } \\
\text { in Uganda }\end{array}$ & White seeded, early maturity and good for brewing. \\
\hline G8 & SESO3 (SRN 39)-Check2 & Sudan & $\begin{array}{l}\text { Released variety } \\
\text { in Uganda }\end{array}$ & $\begin{array}{l}\text { Early maturing, high yielding, good for food and } \\
\text { tolerant to striga, drought and bird damage. }\end{array}$ \\
\hline
\end{tabular}

\subsection{Data Collection and Analysis}

Grain yield data were collected on sorghum genotypes per the (IBPGR, 1993) descriptors. Harvesting was done manually at physiological maturity at all the trial sites. The grain yield data were analysed using combined analysis of AMMI and GGE biplot using PB tools (Version 1.4, http://bbi.irri.org/products) and the models were:

$$
\begin{aligned}
& \mathrm{Y}_{\mathrm{ij}}=\mu+\delta_{\mathrm{i}}+\beta_{\mathrm{j}}+\Sigma_{\mathrm{k}} \hat{\beta}_{\mathrm{k}} \delta_{\mathrm{ik}} \beta_{\mathrm{jk}}+\varepsilon_{\mathrm{ij}} \text { (for AMMI) } \\
& \mathrm{Y}_{\mathrm{ij}}=\mu+\beta_{\mathrm{j}}+Z_{1} \boldsymbol{z}_{\mathrm{k}} \delta_{\mathrm{ik}} \beta_{\mathrm{jk}}+\varepsilon_{\mathrm{ij}} \text { (for GGE Biplot) }
\end{aligned}
$$


Where, $\mathrm{Y}_{\mathrm{ij}}$ is the mean yield of $\mathrm{i}^{\text {th }}$ genotype in $\mathrm{j}^{\text {th }}$ environment, $\mu$ is the overall mean, $\delta_{\mathrm{i}}$ is the genotypic effect, $\beta_{\mathrm{j}}$ is the environment effect, $\lambda_{\mathrm{k}}$ is the singular value for PC axis k, $\delta_{\mathrm{ik}}$ is the genotype eigen vector value for PC axis $\mathrm{n}, \beta_{\mathrm{jk}}$ is the environment eigen vector value for PC axis $\mathrm{k}$ and $\varepsilon_{\mathrm{ij}}$ is the residual error assumed to be normally and independently distributed $\left(0, \sigma^{2} / r\right)$, where $\sigma^{2}$ is the pooled error variance, and $\mathrm{r}$ is the number of replicates (Crossa et al., 2002; Gauch et al., 2008). The mean sorghum grain yield was separated by the least significant difference (LSD) test.

\section{Results and Discussions}

The sorghum grain yield results of the eight (08) sorghum genotypes across the eight (08) environments showed that genotype ICSR 160 had the highest mean grain yield of $2823 \mathrm{Kg} \mathrm{per} \mathrm{ha}^{-1}$, superseded by IESV92043DL, and IS8193 with grain yield of $2783 \mathrm{Kg} \mathrm{ha}^{-1}$ and $2740 \mathrm{Kg} \mathrm{ha}^{-1}$ respectively (Table 3). These genotypes consistently and significantly performed better than the checks across the environments. The combined analysis of variance across the environment for grain yield of eight (08) sorghum genotypes showed that the treatment, genotypes and environment components were significantly different $(P<0.001)$ unlike $G \times E$ interactions at 0.05 level. Our data therefore showed that genotypes and environments used during the study were different. Therefore, there was great diversity between the genotypes. The absence of GEI in this current study clearly indicates breeding for specific adaptability for the targeted trait. According to Andiku et al. (2019), presence of low or no GxE interactions in any study shows that screening programs for such important trait could be conducted centrally at one or two locations to minimise breeding costs.

Table 3. Grain yield of eight sorghum genotypes across the environments

\begin{tabular}{|c|c|c|c|c|c|c|c|c|c|}
\hline Environment & Abi & Iganga & Kitgum & Mayuge & Namutumba & Oyam & Pallisa & Serere & \multirow{3}{*}{$\begin{array}{l}\text { Genotype } \\
\text { means }\end{array}$} \\
\hline Genotype & \multicolumn{8}{|c|}{---------------------------- Grain sorghum yield $\left(\mathrm{Kg} \mathrm{ha}^{-1}\right)$--------------------------- } & \\
\hline GE17/1/2013A & 1808 & 2441 & 2031 & 3702 & 2862 & 3376 & 2024 & 2104 & \\
\hline GE35/1/2013A & 1532 & 2694 & 2014 & 3278 & 2512 & 3334 & 1948 & 2124 & 2430 \\
\hline ICSR 160 & 1710 & 2985 & 2122 & 4091 & 3264 & 3610 & 2167 & 2637 & 2823 \\
\hline IESV92043DL & 1856 & 2977 & 2127 & 3859 & 3224 & 3566 & 2082 & 2576 & 2783 \\
\hline IESV92172DL & 1739 & 2488 & 1987 & 3208 & 2882 & 2837 & 1967 & 1647 & 2344 \\
\hline IS8193 & 2126 & 3077 & 2239 & 3563 & 2864 & 3382 & 2199 & 2471 & 2740 \\
\hline SESO1 (Check1) & 1576 & 2507 & 2067 & 3596 & 2634 & 3426 & 2023 & 2016 & 2481 \\
\hline SESO3 (Check2) & 1524 & 2599 & 2001 & 3752 & 3100 & 3156 & 1999 & 2097 & 2529 \\
\hline Mean & 1734 & 2721 & 2074 & 3631 & 2918 & 3336 & 2051 & 2209 & 2584 \\
\hline $\operatorname{LSD}(0.05)$ & $538.7 \mathrm{~ns}$ & & & & & & & & \\
\hline C.V \% & 18.4 & & & & & & & & \\
\hline
\end{tabular}

Note. ns: not significant at level 0.05 .

According to Akter et al. (2014), a genotype or an environment is assumed to have small interaction (stable) when the first Interaction Principal Component Axis (IPCA1) score is almost to zero or equivalent to zero. More still, the horizontal line (y-ordinate) is the IPCA1 value of zero while the vertical line represents the grand mean for grain yield (Figure 2) where a genotype or environment on the right side of the vertical line are high yielding unlike their counter parts on the left hand side of the vertical line. However, genotypes and environments that appear on perpendicular and horizontal lines have similar mean and interaction patterns respectively (Akter et al., 2019). Consequently, our study provided a visual expression of the relationships between the IPCA1 and means of genotypes and environments as shown in Figure 2. The AMMI biplot showed four groupings of genotypes; IESV92172DL (G5) generally low yielding and unstable, GE17/1/2013A (G1), GE35/1/2013A (G2), SESO1 (G7), and SESO3 (G8), low yielding and moderately stable, IESV92043DL (G4) high yielding and the moderately stable while ICSR 160 (G3) and IS8193 (G6) are high yielding but unstable. 


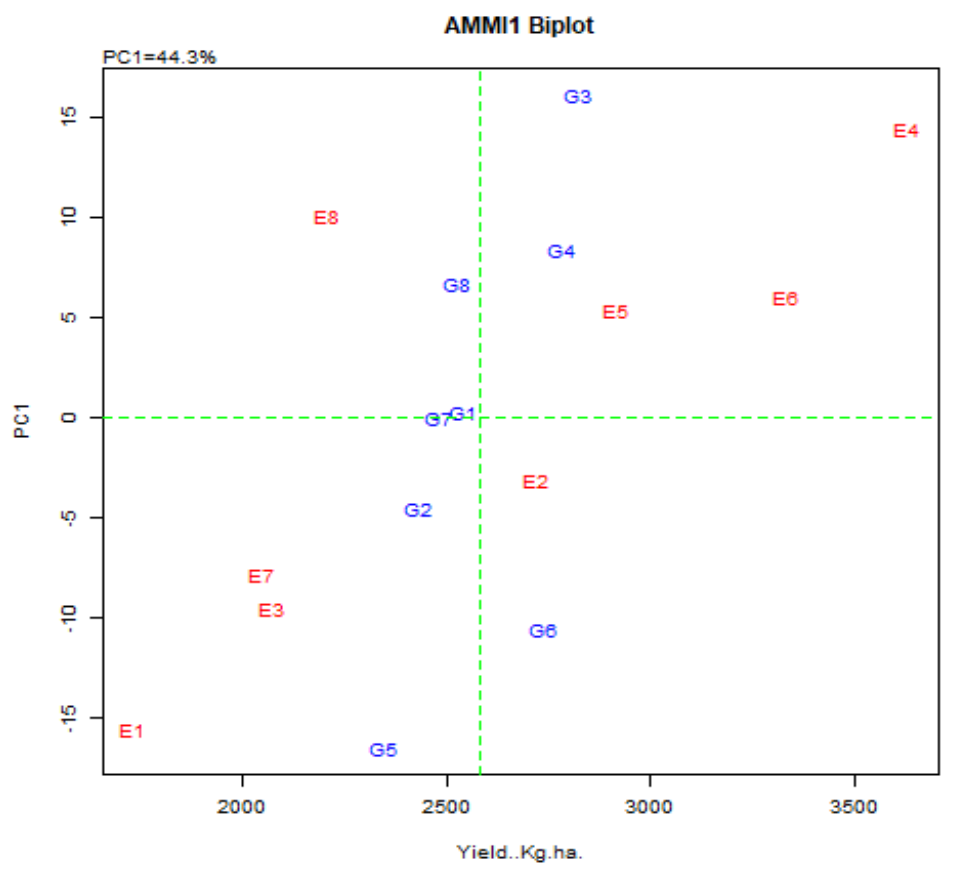

Figure 2. AMMI biplot (genotypes and environments plotted against their IPCA1 scores) for sorghum grain yield in $\mathrm{Kg}$ per hectare

Out of the eight (08) environments, half of the environments; Iganga (E2), Mayuge (E4), Namutumba (E5) and Oyam (E6) were high yielding since they were positioned on the right side of the vertical line with Iganga (E2) being the most stable environment since its Interaction Principal Component Axis (IPCA) scores was close to zero than other environments while the low yielding environments were positioned at the left side of the vertical line [Arua (E1), Kitgum (E3), Pallisa (E7) and Serere (E8)]. The genotype or environment IPCA scores (either positive or negative) displays their stability in the AMMI biplot. The more the IPCA score is close to zero (low interaction), the more stable the genotype or environment as opposed to environments (or genotypes) with large first IPCA scores (high interactions).

The pattern of GEI was cross-validated from distribution of eight sorghum genotypes over eight environments on the AMMI display of the first and second IPCA of genotypes and the environment (AMMI 2 model) as proposed by Vargas et al. (2001). This second model of AMMI helps to further examine adaptation of the genotypes across the environment (Figure 3). More still, (Purchase, 1997) explained the stability pattern of genotype display in AMMI 2 model where he emphasised that the stable genotypes are closer to the centric ring of the biplot. Based on this argument, Figure 3 results further showed that, GE17/1/2013A (G1) and SESO1 (G7) being more stable based on their closeness to the centric ring of the biplot. Conversely, ICSR 160 (G3) and IESV92172DL (G5) had diffused position therefore they were considered unstable across the study environment. The AMMI 2 model biplot further showed that genotypes ICSR 160 (G3) and IESV92172DL (G5) and environments Abi (E1), Mayuge (E4) and Namutumba (E5) contributed more to the GE interaction effect. 


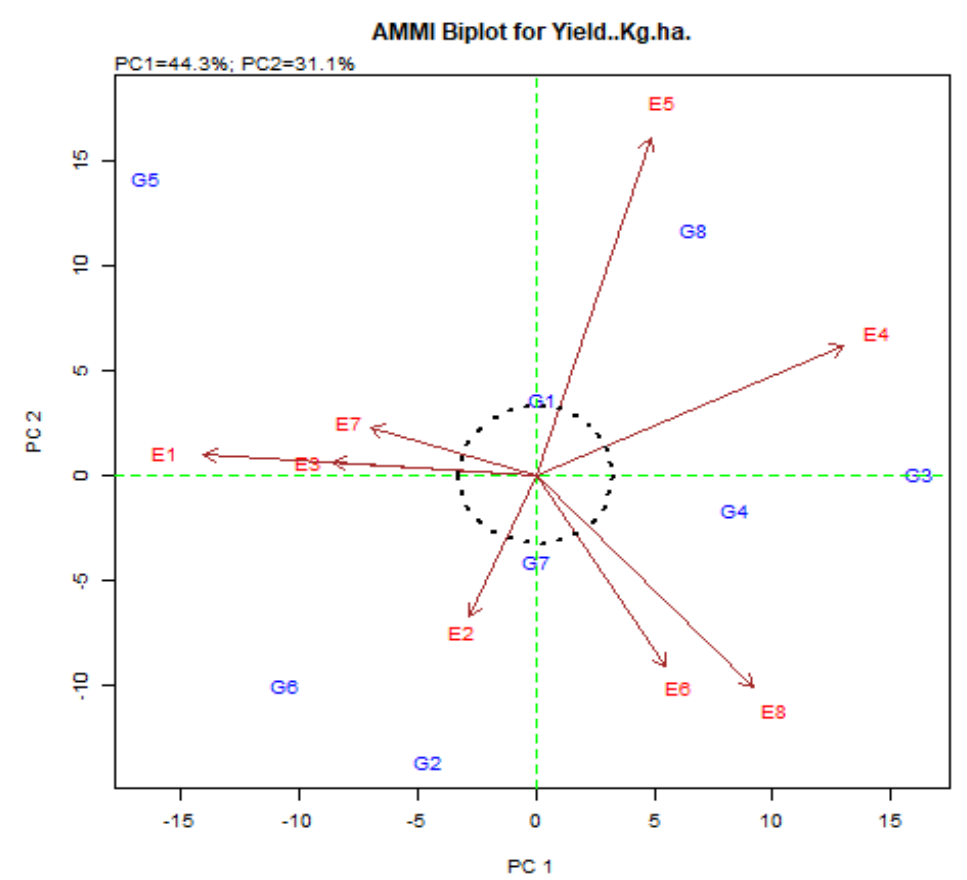

Figure 3. AMMI 2 biplot (IPCA2 scores plotted against IPCA1 scores) for sorghum grain yield in Kg per hectare

SESO3 (G8) and ICSR 160 (G3) were specifically adapted to Namutumba (E5) and Mayuge (E4) respectively. On contrary, GE35/1/2013A (G2) and IS8193 (G6) were specifically adapted to Iganga (E2). The observed results can be attributed to fundamental GEI (Wallace et al., 1995). More still, the GGE biplot informative and representativeness is of great significant measure of testing environments. The visual length of the environment vectors which is proportional to the standard deviation within the respective environments determines the environmental discriminatory ability. Superior environmental discriminating ability is displayed by the extensiveness of the environment vector. Consequently, in this study, the environmental vector biplot identified Abi (E1), Mayuge (E4) and Namutumba (E5) as favourably informative (discriminating) for the trial genotypes, as revealed by the extensive environment vectors (Figure 3) therefore exert strong interaction with genotype. Informative test environments precisely fix differences among the genotype accordingly inform breeders on selection decision. Iganga (E2) was non informative (least discriminating) of the eight (08) environments followed by Pallisa (E7), as revealed by the minuscule environment vector. The non-informative trial environments like Iganga (E2) and Pallisa (E7) tends to furnish little information on the genotypes therefore should not be used as trial environments. More still, a trial environment with smaller Average-Environment Axis (AEA) angle is more representative than their counter parts. The AEA (the line that passes through the average environment and the biplot origin) measures the representativeness of the average environment. Trial environments that are both informative and representative are superior environments for selecting overall genotype with good adaptability. Therefore, testing sorghum genotype for grain yield solely in Abi (E1) and Mayuge (E4) is adequate based on their representative and informative ability for sorghum grain yield in the study. Namutumba (E5) is informative but not representative due to its dispersed position; hence such environment can be used for rapid elimination of unstable genotypes during the selection process (Tukamuhabwa et al., 2012) under a single mega-environment or for selecting genotypes under mega-environments for specific adaptability. Use of those particular environments with non-informative and representative ability for assessing sorghum grain yield may give ambiguous results due to their low informative and representative ability. Yan and Rajcan (2002) defined the superior environment as the environment with substantial PC1 scores (informative) and small PC2 scores (representative) as observed for Abi (E1).

GGE biplot for the environment vector view for the stability study of genotypes for sorghum grain yield over the eight (08) environments identified the genotype IESV92043DL (G4) as the stable genotypes with fairly high sorghum grain yield mean performance (Figure 4). The biplot origin represents a stable genotype with grand mean value and thus zero contribution of the additive effect of genotype and multiplicative interactions shows the stability of the genotype. However, based on the same principle, SESO1 (G7) was identified as stable genotype but with low sorghum grain yield mean performance. This result was not surprising since SESO1 (G7) 
was a released registered commercial cultivar which has already adapted in these environments. The distance between two genotypes estimates the Euclidean distance between them consequently measuring the dissimilarity between the genotypes. In this study, all the used genotypes are quite different in their genetic make-up with respect to sorghum grain yield due to their diffuse position (Figure 4). Out of the eight (08) environments, Mayuge (E4) was found to be the most superior environment in terms of sorghum grain yield performance and genotype, ICSR 160 (G3) was best adapted to Mayuge (E4) and Namutumba (E5) while IESV92043DL (G4) was specifically best adapted to Oyam (E6). Therefore, ICSR 160 (G3) and IESV92043DL (G4) with a particular adaptation to environments; Mayuge (E4)/Namutumba (E5) and Oyam (E6) respectively could be selected and recommended for specific adaptability as observed in this study.

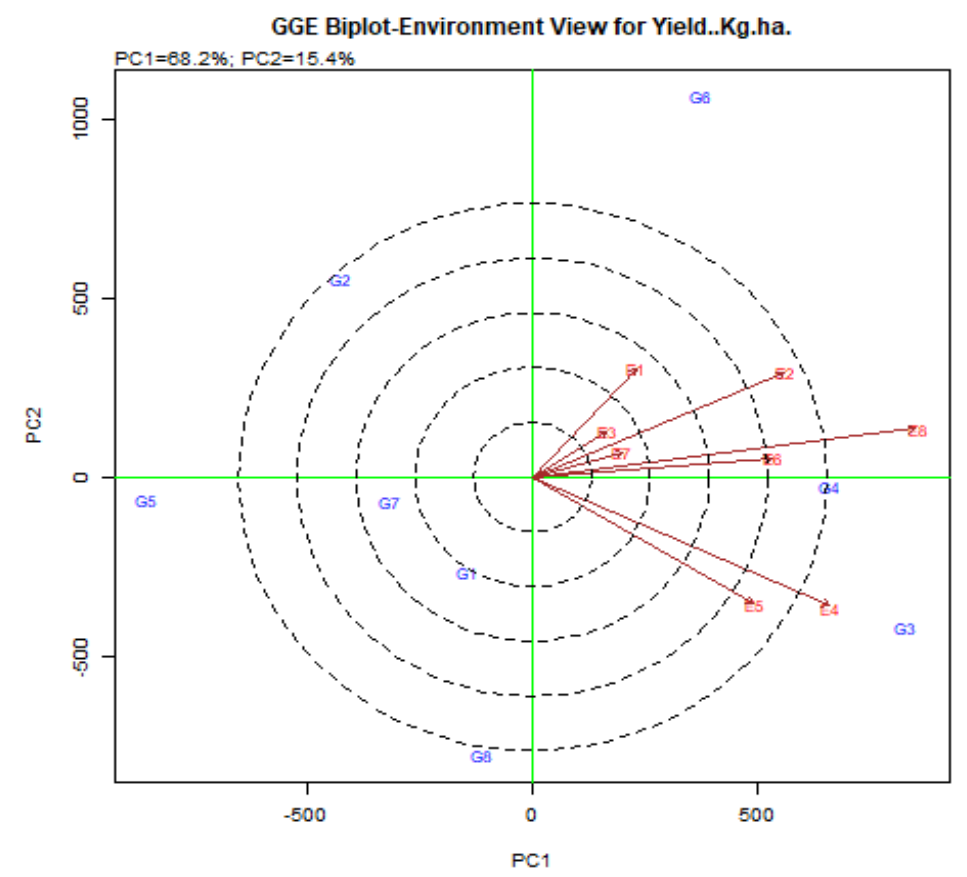

Figure 4. GGE biplot for the environment vector view to show similarities among the environments

On contrary, genotype focused biplot (Figure 5) conveyed that IESV92043DL (G4) is the most stable genotype for sorghum grain yield in the entire study environment while ICSR 160 (G3) is the superior genotype, succeeded by IESV92043DL (G4) and IS8193 (G6) respectively. However, IESV92043DL (G4) was depicted as superior genotype in the entire study environments due to its outstanding relative stability and adaptability couple with moderate sorghum grain yield from AMMI and GGE biplots display. This is a desirable plant breeding trait consequently such genotype can be recommended for possible release as a variety to up take pathway. The genotypic stability displayed in the study indicated that it performs well regardless of the GxE interaction thus wide adaptability of the genotype. 


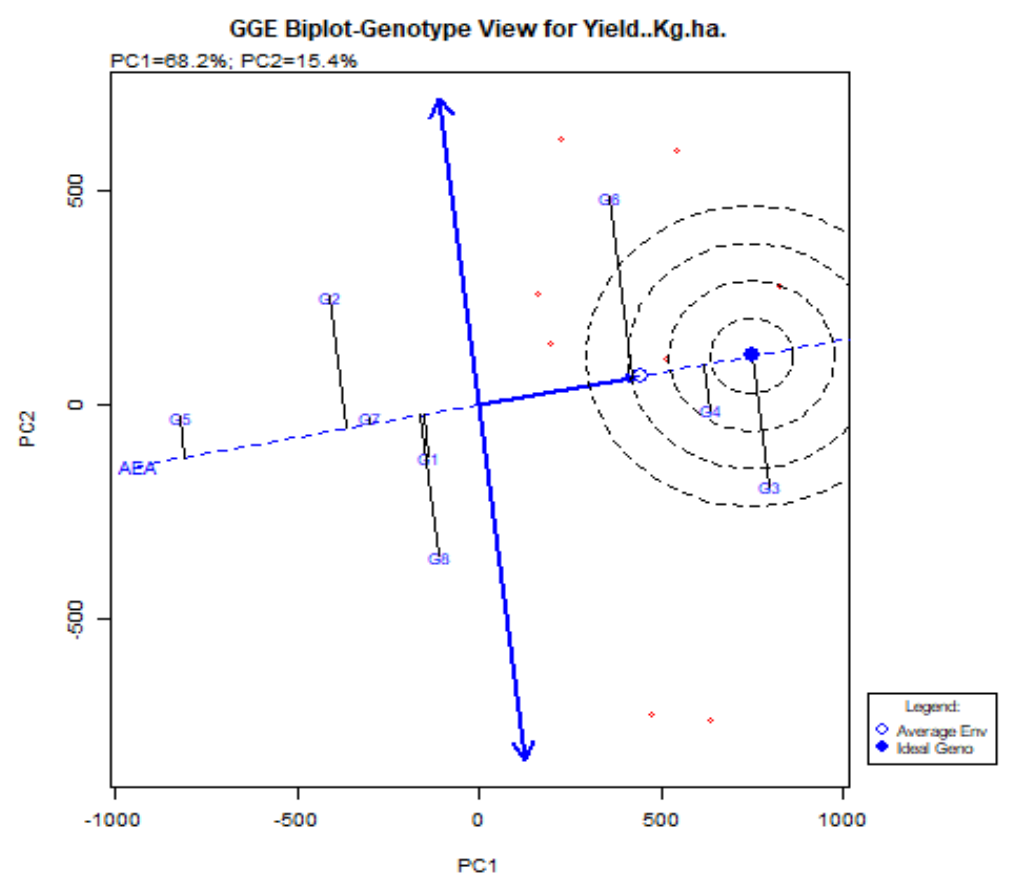

Figure 5. GGE biplot for the genotype view to show genotype ranking relative to an ideal genotype

The dynamic stability displayed by the genotypes calls for specific selection of genotypes suitable for particular environments (Andiku et al., 2019). However, genotypes; GE17/1/2013A (G1), GE35/1/2013A (G2), IESV92172D (G5), SESO1 (G7), and SESO3 (G8) recorded low yield unlike their counter parts [ICSR 160 (G3), IESV92043DL (G4) and IS8193 (G6)] that had high yields as evidenced by their positioning on the right side of the AEC abscissa (single-arrowed line (Figure 5). These high yielding genotypes could be selected for possible release as a variety. On the other hand, genotypes with below-average mean (left side of the AEC abscissa); SESO1 (G7) and GE17/1/2013A (G1) which are stable could be selected. The extensiveness of the non-arrowed line to the AEC regardless of the direction, indicates that genotype is unstable (high level of GEI) in the entire test environments. Conversely, genotypes IESV92043DL (G4)/SESO1 (G7) and GE17/1/2013A (G1) were fairly stable as well as high and low yielding respectively in terms of grain yield performance.

Physical envision of the which-won-where pattern of Multi Environment Yield Trials (METs) data is very crucial for understanding possible existence of different mega-environments (ME) in the production area as cited by Singh et al. (2019). The display of GGE-biplot clearly shows which-won-where pattern, as such it concisely summarises the GEI pattern of a trial as displayed for sorghum grain yield data in Figure 6. In the current study, there are four sectors with two mega environments namely Mega Environment I consisting of Abi (E1), Iganga (E2), Kitgum (E3), and Pallisa (E7) with the best genotype being IS8193 (G6). Mega environment II had the environments; Mayuge (E4), Namutumba (E5), Oyam (E6) and Serere (E8) with the best genotype being ICSR 160 (G3). These results suggested that genotypes with high grain yield for these two mega environments were ICSR 160 (G3) and IS8193 (G6) as observed under AMMI biplot (Figure 2). However Mega Environment II also had IESV92043DL (G4) with specific adaptability to Oyam (E6). These Mega Environment suggests feasible existence of different mega environments for sorghum production across the country. According to Oral et al. (2018), environments that are positioned within the same sector have strong correlations, and GEI suggesting effect of the environment on the genotypes and the presence of mega environment which is observed in this current study. 


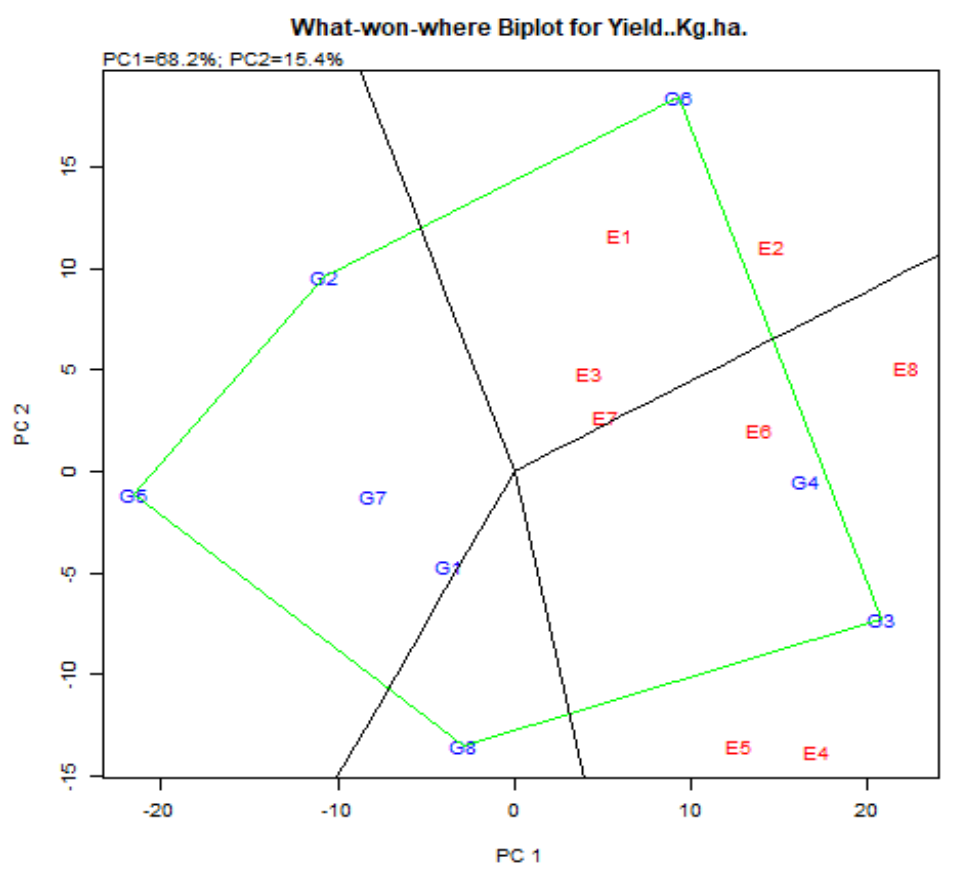

Figure 6. IPCA2 scores plotted against IPCA1 scores based on sorghum grain yield across eight environments to show the which-won-where pattern

The fascinating point from this GGE biplot view is that the genotypes [ICSR 160 (G3), IESV92043DL (G4), and IS8193 (G6)] that fall within the two mega environments were genotypes that out-performed the registered commercial released cultivar [(SESO1(G7) and SESO3 (G8)]. No environments fell into sectors with genotypes; GE17/1/2013A (G1), GE35/1/2013A (G2), IESV92172DL (G5), SESO1(G7) and SESO3 (G8) as vertices, suggesting that these genotypes did not perform well in any of the eight (08) environments. However, this Mega Environment pattern needs further verifying through setting repeated seasonal trials across the study location since this Mega Environment pattern was solely deduced from two seasons data of 2017 without considering subsequent years.

\section{Conclusion}

In this study, both the AMMI and GGE models identified IESV92043DL (G4) as the ideal genotype as it was stable and high yielding across the entire study environments. Using the same data, the three (03) promising sorghum genotypes [ICSR 160 (G3), IESV92043DL (G4) and IS8193 (G6)] with grain yield gain of 11.6\%, $10.0 \%$ and $8.3 \%$ over the check (SESO3) respectively were identified and released as varities in Uganda; NAROSORG1, NAROSORG3, and NAROSORG2 respectively. On the other hand, stable genotype GE17/1/2013A (G1) with below-average yield mean of $2544 \mathrm{Kg}^{-1}$ was released as NAROSORG4 because of being resistant to covered kernel smut.

Abi (low yielding) and Mayuge (high yielding) were the most representative and informative environment in the country for sorghum grain yield performance and only testing sorghum genotypes for grain yield performance in these two environments can be enough. Namutumba can be used for rapid elimination of unstable genotypes during the selection process since it was informative but not representative.

The test environments for sorghum grain yield performance were delineated into two presumed mega-environments but this Mega Environment pattern needs further verifying through setting repeated seasonal trials across the study location since this Mega Environment pattern was solely deduced from two seasons data of 2017 without considering subsequent years.

\section{Acknowledgements}

This publication is an output from research projects funded by Alliance for a Green Revolution in Africa (AGRA), Harnessing Opportunities for Productivity Enhancement (HOPE II) project funded by Bill Melinda Gate foundation and the Ugandan National Agricultural Research Organisation (NARO). We thank Dr. Eric Manyasa of ICRISAT and Dr. Gichuru Lillian of AGRA for their technical input. We would also like to thank Mr. Amayo Robert of Busitema University for editing the work. 


\section{References}

Akter, A., Hasan, M., \& Kulsum, M. (2019). Stability and adaptability of promising hybrid rice genotypes in different locations of Bangladesh. Adv. Plants Agric. Res., 9(1), 35-39. https://doi.org/10.15406/apar.2019. 09.00407

Akter, A., Jamil, H., Umma, K., Islam, M., Hossain, K., \& Mamunur, R. (2014). AMMI biplot analysis for stability of grain yield in hybrid rice (Oryza sativa L.). J. Rice Res., 2(2), 126. https://doi.org/10.4172/ jrr.1000126

Andiku, C., Tukamuhabwa, P., Ssebuliba, J. M., Talwana, H., Tumwegamire, S., \& Gruneberg, W. (2019). Evaluation of the American yam bean (Pachyrhizus spp.) for storage root yield across varying eco-geographic conditions in Uganda. Journal of Agricultural Science, 11(8), 100. https://doi.org/10.5539/ jas.v1 1 n 8 p 100

Crossa, J., Cornelius, P. L., \& Yan, W. J. C. S. (2002). Biplots of linear-bilinear models for studying crossover genotype $\times$ environment interaction. Crop Science, 42(2), 619-633. https://doi.org/10.2135/ cropsci2002.6190

Gauch, H. G., Piepho, H.-P., \& Annicchiarico, P. J. C. S. (2008). Statistical analysis of yield trials by AMMI and GGE: Further considerations. Crop Science, 48(3), 866-889. https://doi.org/10.2135/cropsci2007.09.0513

IBPGR (International Board for Plant Genetic Resources). (1993). Descriptors for sorghum [Sorghum bicolor (L.) Moench]. International Board for Plant Genetic Resources, Rome, Italy.

Kaya, Y., Palta, C., \& Taner, S. (2002). Additive main effects and multiplicative interactions analysis of yield performances in bread wheat genotypes across environments. Turkish Journal of Agriculture and Forestry, 26(5), 275-279.

Lubadde, G., Tongoona, P., Derera, J., \& Sibiya, J. (2017). Analysis of Genotype by Environment Interaction of Improved Pearl Millet for Grain Yield and Rust Resistance. Journal of Agricultural Science, 9(2), 188-195. https://doi.org/10.4314/ujas.v17i1.6

Nyaligwa, L. M., Shimelis, H., Mwadzingeni, L., \& Laing, M. D. (2018). Genotype-by-environment interaction analysis of maize hybrids for grain yield and maize streak virus severity in the mid-altitude agro-ecologies. Australian Journal of Crop Science, 12(8), 1304. https://doi.org/10.21475/ajcs.18.12.08.PNE1108

Oral, E., Kendal, E., \& Dogan, Y. J. F. E. B. (2018). Selection the best barley genotypes to multi and special environments by AMMI and GGE biplot models. Fresenius Environmental Bulletin, 27(7), 5179-5187.

Purchase, J. L. (1997). Parametric analysis to describe genotype $\times$ environment interaction and yield stability in winter wheat $(\mathrm{PhD}$ thesis, University of the Orange Free State, South Africa).

Rakshit, S., Ganapathy, K., Gomashe, S., Dhandapani, A., Swapna, M., Mehtre, S., ... Jadhav, B. J. T. J. O. A. S. (2017). Analysis of Indian post-rainy sorghum multi-location trial data reveals complexity of genotype $\times$ environment interaction. The Journal of Agricultural Science, 155(1), 44-59. https://doi.org/10.1017/ S0021859616000137

Singh, C., Gupta, A., Gupta, V., Kumar, P., Sendhil, R., Tyagi, B., Singh, G., Chatrath, R., Singh, G. J. C. B., \& Biotechnology, A. (2019). Genotype $\times$ environment interaction analysis of multi-environment wheat trials in India using AMMI and GGE biplot models. Crop Breeding and Applied Biotechnology, 19(3), 309-318. https://doi.org/10.1590/1984-70332019v19n3a43

Tukamuhabwa, P., Asiimwe, M., Nabasirye, M., Kabayi, P., \& Maphosa, M. (2012). Genotype by environment interaction of advanced generation soybean lines for grain yield in Uganda. African Crop Science Journal, 20(2), 107-116. https://doi.org/10.1007/s10681-011-0404-3

Vargas, M., Crossa, J., van Eeuwijk, F., Sayre, K. D., \& Reynolds, M. P. (2001). Interpreting treatment $\times$ environment interaction in agronomy trials. Agronomy Journal, 93(4), 949-960. https://oi.org/10.2134/ agronj2001.934949x

Wallace, D., Yourstone, K., Baudoin, J.-P., Beaver, J. S., Coyne, D. P., White, J. W., \& Zobel, R. (1995). Photoperiod $\times$ temperature interaction effects on the days to flowering of bean (Phaseolus vulgaris L.). In M. Pessarakli (Ed.), Handbook of plant and crop physiology.

Yan, W., \& Rajcan, I. (2002). Biplot analysis of test sites and trait relations of soybean in Ontario. Crop Science, 42(1), 11-20. https://doi.org/10.2135/cropsci2002.1100 
Zobel, R. W., Wright, M. J., \& Gauch, H. G. (1988). Statistical analysis of a yield trial. Agronomy journal, 80(3), 388-393. https://doi.org/10.2134/agronj1988.00021962008000030002x

\section{Copyrights}

Copyright for this article is retained by the author(s), with first publication rights granted to the journal.

This is an open-access article distributed under the terms and conditions of the Creative Commons Attribution license (http://creativecommons.org/licenses/by/4.0/). 